\title{
Centros comerciales: transformaciones en el territorio y la vida cotidiana.
}

\author{
Elaborado por: Carolina Garzón Medina, \\ Aidaluz Sánchez Arismendi, \\ María Paula Neira, \\ María Alejandra Rincón, \\ Angélica Cañón, \\ Alejandra Páez, \\ Angie Mendoza, \\ Jennifer González,
}

El centro comercial ha sido un lugar clave en la transformación de las ciudades y en especial en la forma en la que el ser humano se relaciona, ocio y consumo se encuentran en dicho lugar, dando espacio para que en tan solo unos metros cuadrados se pueda evidenciar diversos fenómenos. En la actualidad, los centros comerciales han trasformado el paisaje y la infraestructura urbana, así por ejemplo, los edificios coloniales se han convertido en "megacentros"; antiguos barrios residenciales se convierten en centros de ocio y consumo; y se acondiciona la malla vial para el acceso y la movilidad de los habitantes para el disfrute de estos lugares de consumo.

Adicional a estos cambios, los centros comerciales están diseñados para construir una ilusión de igualdad de acceso a símbolos, experiencias, información, ideales y status. Sin embargo, las posibilidades de compra en las tiendas, son las que empiezan a marcar las diferencias entre clases sociales a partir de referencias universales (logotipos, siglas, etiquetas) que generan un sentido de distinción y de pertenencia a un grupo social.

Si bien el centro comercial se asocia con las dinámicas urbanas, es éste lugar una vía de escape a las principales problemáticas de la ciudad (inseguridad, desorden, contaminación, marginalidad, entre otras). Así, éste lugar es planeado y estandarizado, que para el visitante o el extranjero le resulta familiar, identificando espacios, experiencias, sentimientos y marcas comunes; es un sitio que ofrece 
vigilancia particular a las personas que lo visitan; es un espacio público pero de propiedad privada regulado por normas y reglas en las que se estipula quien, qué y cómo se vende.

Estas características no solo responden a las dinámicas de las grandes ciudades, dado que la presencia de estos se ha venido incrementando en zonas aledañas a las grandes ciudades transformado de manera paulatina las dinámicas de vida, hábitos de consumo, modos de relacionamiento y apropiación del territorio. Es el caso de Mosquera (Cundinamarca), municipio aledaño a la capital del país, en el que cohabitan prácticas rurales (principalmente agroindustriales) y urbanas. Éste municipio cuenta con un gran centro comercial (Eco Plaza) desde el 2015, en el que además de ofrecer servicios tradicionales (cine, plazoletas de comidas, ropa y accesorios) se articula con las necesidades de los habitantes de los barrios aledaños, ofreciendo así ferias artesanales, jornadas de salud (vacunación, donación de sangre, servicios complementarios, entre otros) y celebraciones litúrgicas. Así mismo, ha generado cambios en los estilos de vida de los habitantes del sector, como por ejemplo dificultades en la movilidad a causa del aumento de tráfico en la zona, aumento de la sensación de inseguridad por la presencia de personas diferentes a los vecinos y la fragmentación en las relaciones barriales.

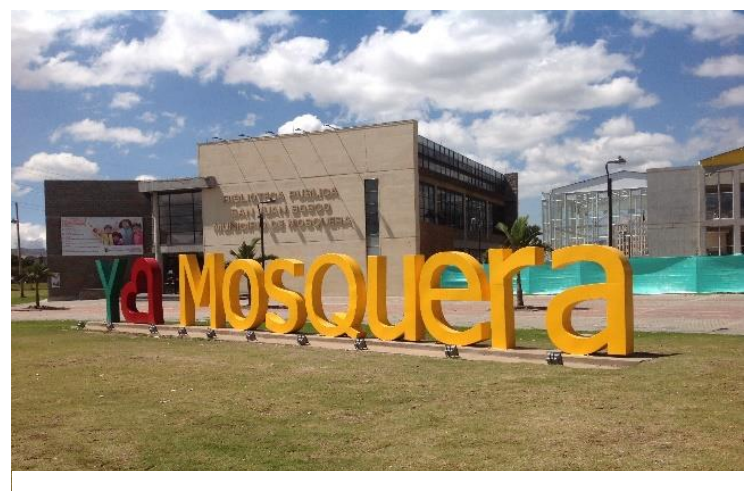

Tomado de: https://commons.wikimedia.org
Éstas transformaciones son objeto de estudio de los semilleros "Neuroconsumer" de la Facultad de Mercadeo y "Sociedad y Consumo" de la Facultad de Sociología, quienes a través de un ejercicio formativo de investigación se han venido aproximando a las dinámicas propias de

la zona a través de los líderes comunales y habitantes de los barrios aledaños al "Mall", indagando por lo que significa el territorio en el que habitan, las dinámicas de compra, 
consumo y modos de vida que llevan actualmente, y con ello lograr proponer estrategias que mejoren las relaciones entre comercio y vida barrial. 